\title{
Neuroblastoma treatment in the post-genomic era
}

\author{
Maria Rosaria Esposito ${ }^{1 * \dagger}$, Sanja Aveic ${ }^{1 \dagger}$, Anke Seydel $^{2}$ and Gian Paolo Tonini ${ }^{1}$
}

\begin{abstract}
Neuroblastoma is an embryonic malignancy of early childhood originating from neural crest cells and showing heterogeneous biological, morphological, genetic and clinical characteristics. The correct stratification of neuroblastoma patients within risk groups (low, intermediate, high and ultra-high) is critical for the adequate treatment of the patients. High-throughput technologies in the Omics disciplines are leading to significant insights into the molecular pathogenesis of neuroblastoma. Nonetheless, further study of Omics data is necessary to better characterise neuroblastoma tumour biology. In the present review, we report an update of compounds that are used in preclinical tests and/or in Phase I-II trials for neuroblastoma. Furthermore, we recapitulate a number of compounds targeting proteins associated to neuroblastoma: MYCN (direct and indirect inhibitors) and downstream targets, Trk, ALK and its downstream signalling pathways. In particular, for the latter, given the frequency of ALK gene deregulation in neuroblastoma patients, we discuss on second-generation ALK inhibitors in preclinical or clinical phases developed for the treatment of neuroblastoma patients resistant to crizotinib.

We summarise how Omics drive clinical trials for neuroblastoma treatment and how much the research of biological targets is useful for personalised medicine. Finally, we give an overview of the most recent druggable targets selected by Omics investigation and discuss how the Omics results can provide us additional advantages for overcoming tumour drug resistance.
\end{abstract}

Keywords: Neuroblastoma, Omics, Personalised medicine, Targeted therapy

\section{Background}

Neuroblastoma is an embryonal malignancy of early childhood of the sympathetic nervous system belonging to the neuroblastic tumors that also include ganglioneuroblastoma and ganglioneuroma. The nosologic group of neuroblastoma is very heterogeneous in terms of biologic, genetic, clinical and morphologic characteristics $[1,2]$. Neuroblastoma presents with a poor prognosis for individuals diagnosed at over 18 months of age with disseminated disease as metastatic processes in liver, bone marrow, skin and several other organs [3]. The highly heterogeneous clinical behaviour of disease makes the prediction of the patient's individual risk at the time of diagnosis the major goal in choosing an adequate therapeutic approach. Many efforts done by performing the so called "Omics" technologies have shed light on

\footnotetext{
* Correspondence: mr.esposito@irpcds.org

${ }^{\dagger}$ Equal contributors

${ }^{1}$ Paediatric Research Institute, Fondazione Città della Speranza,

Neuroblastoma Laboratory, Corso Stati Uniti, 4, Padua 35127, Italy

Full list of author information is available at the end of the article
}

the biology of this tumour allowing more accurate stratification of the patients in proper risk group.

In fact, by combining the results of Omics data and available clinical/biological parameters, the International Neuroblastoma Risk Group (INRG) task force has established a stratification system of neuroblastoma patients taking into consideration diverse prognostic factors (i.e., clinical stage, patient's age at diagnosis, tumour histology (Shimada system) [4], grade of tumour differentiation, MYCN oncogene amplification, 11q deletion and DNA ploidy). Based on these criteria, neuroblastoma patients are currently subdivided into (very) low-, intermediate-, high- and ultra-high-risk groups. Nowadays, about half of all diagnosed cases are classified as high-risk (HR) for disease relapse, while overall survival rates still show only modest improvement, less than $40 \%$ at 5 years [5], Therefore, recent discoveries regarding the understanding of the genetic basis of neuroblastoma and Omics data should necessarily be integrated in current knowledge of this malignancy in order to assure more accurate diagnosis 
for each patient and ascertain a good medical practice in terms of personalised therapy. In this regard, the awareness of the sequence of the entire human genome and the development of high-throughput Omics technologies has changed the approach to study neuroblastoma. Genomewide information of amplifications and deletions of genomic regions, or somatically acquired genetic variations, common predisposing genetic variants and mRNA expression profiles have greatly helped us in better understanding of tumour behaviour. In this review we provide an overview on recent Omics studies, and how they direct current and future therapeutic approaches, shaping in that way the clinical trials set for neuroblastoma patients.

\section{Therapeutic solutions to approach the treatment of neuroblastoma Immunotherapy}

The HR patients require very intensive treatments, including chemotherapy, surgery, radiotherapy, myeloablative chemotherapy with stem cell rescue, immunotherapy with anti-GD2 (disialoganglioside, tumour-associated surface antigen) antibody and differentiation therapy with 13-cis retinoic acid. However, new clinical trials for HR neuroblastoma patients are ongoing: i) a phase III trial that demonstrated significant improvement in event-free survival after combined immunotherapy with granulocytemacrophage colony-stimulating factor GM-CSF, IL-2 and the ch14.18 anti-GD2 antibody (NCT00026312; list of all clinical trials discussed here can be found in Table 1) [6]; ii) a phase III randomized study (SIOPEN) for isotretinoin (13-cis-RA) and ch14.18 efficacy testing, in combination or not with IL-2 and after autologous stem cell transplantation (NCT01704716) [7]; and iii) two trials using L1-cell adhesion molecule (L1-CAM) together with GD2-specific chimeric antigen receptors (CARs) to demonstrate antitumour activity in intensely treated relapsed or refractory neuroblastoma patients (NCT01822652) [8]. The results of the listed trials are expected in 2017 and onwards.

\section{Targeting MYCN}

For more than 30 years, MYCN status (amplified versus single copy) has been determined to be one of the strongest biological markers for neuroblastoma, providing a negative prognosis for a subset of patients with amplified $M Y C N$ [9-12]. Since a discovery of a correlation between $M Y C N$, rapid tumour progression and poor prognosis of neuroblastoma patients, many efforts have been made in developing suitable MYCN drug that could impair its functions, and the same attempts are still ongoing. This is because of difficulties in developing an optimal therapy

Table 1 Drugs of clinical trials for HR neuroblastoma interventetion

\begin{tabular}{|c|c|c|c|c|}
\hline ClinicalTrials ID & Original study & Phase & Status & Reference $^{a}$ \\
\hline NCT00026312 & $\begin{array}{l}\text { Isotretinoin With or Without Dinutuximab, Aldesleukin } \\
\text { and Sargramostim Following Stem Cell Transplant in } \\
\text { Treating Patients With Neuroblastoma }\end{array}$ & phase III & Completed & Yu AL et al., 2010 [6] \\
\hline NCT01704716 & $\begin{array}{l}\text { High Risk Neuroblastoma Study } 1.7 \text { of SIOP-Europe } \\
\text { (SIOPEN) }\end{array}$ & phase III & Recruiting & Dobrenkov K \& Cheung NK, 2014 [7] \\
\hline NCT01822652 & $\begin{array}{l}\text { 3rd Generation GD-2 Chimeric Antigen Receptor and } \\
\text { iCaspase Suicide Safety Switch, Neuroblastoma, GRAIN }\end{array}$ & phase I & Active, not recruiting & Heczey A \& Louis CU, 2013 [8] \\
\hline NCT02395666 & $\begin{array}{l}\text { Preventative Trial of Difluoromethylornithine (DFMO) in } \\
\text { High Risk Patients With Neuroblastoma That is in } \\
\text { Remission }\end{array}$ & Phase 2 & Active, not recruiting & Wallick CJ et al., 2005 [64] \\
\hline NCT01586260 & $\begin{array}{l}\text { Preventative Trial of DFMO in Patients With High Risk } \\
\text { Neuroblastoma in Remission }\end{array}$ & Phase 2 & Active, not recruiting & Wallick CJ et al., 2005 [64] \\
\hline NCT01059071 & $\begin{array}{l}\text { Safety Study for Refractory or Relapsed Neuroblastoma } \\
\text { With DFMO Alone and in Combination With Etoposide }\end{array}$ & Phase 1 & Completed & Wallick CJ et al., 2005 [64] \\
\hline NCT02097810 & $\begin{array}{l}\text { Study of Oral RXDX-101 in Adult Patients With Locally } \\
\text { Advanced or Metastatic Cancer Targeting NTRK1, } \\
\text { NTRK2, NTRK3, ROS1 or ALK Molecular Alterations }\end{array}$ & phase I & Recruiting & Lee J et al., 2015 [83] \\
\hline NCT01742286 & $\begin{array}{l}\text { Phase I Study of LDK378 in Pediatric, Malignancies With } \\
\text { a Genetic Alteration in Anaplastic Lymphoma Kinase } \\
\text { (ALK) }\end{array}$ & phase I & Recruiting & Schulte JH et al., 2013 [69] \\
\hline NCT01871805 & $\begin{array}{l}\text { A Study of CH5424802/RO5424802 in Patients With } \\
\text { ALK-Rearranged Non-Small Cell Lung Cancer }\end{array}$ & phase $\|$ & Active, not recruiting & McKeage K, 2015 [86] \\
\hline NCT01049841 & $\begin{array}{l}\text { Perifosine With Temsirolimus for Recurrent Pediatric } \\
\text { Solid Tumors }\end{array}$ & phase I & Active, not recruiting & Rodrik-Outmezguine VS et al., 2011 [104] \\
\hline NCT01767194 & $\begin{array}{l}\text { Irinotecan Hydrochloride and Temozolomide With } \\
\text { Temsirolimus or Dinutuximab in Treating Younger } \\
\text { Patients With Refractory or Relapsed Neuroblastoma }\end{array}$ & Phase 2 & Recruiting & Geoerger B et al., 2012 [105] \\
\hline
\end{tabular}

${ }^{a}$ References are cited in review manuscript 
against MYCN due to a lack of appropriate surfaces on its DNA-binding domain to which drugs can bind. This problem persists not only for MYCN but also for other Myc family members [13]. Therefore, at present, a more widely accepted approach for MYCN regulation involves its indirect targeting [14].

\section{Indirect targeting of MYCN expression and function}

A number of compounds currently in use for the cure of neuroblastoma patients have been tested for their capacity to down-regulate MYCN expression. Among these compounds are retinoic acid [15] and other MYCN non-specific inhibitors such as HDAC inhibitors $[16,17]$ or inhibitors of the PI3K/AKT/mTOR pathway $[18,19]$. The capacity of these compounds to down-regulate MYCN expression has been confirmed, but their effectiveness is variable. Therefore, other strategies have been adopted to target MYCN indirectly, by altering the function of other proteins known to regulate MYCN protein stability or by manipulating downstream targets of MYCN [20, 21].

\section{Aurora $A$ and Aurora B inhibitors}

The serine/threonine kinases Aurora A (AURKA) and Aurora B (AURKB) are crucial regulators of the cell cycle. Their coding genes differ in subcellular distribution and the protein products in their specific functions [22]. AURKA stabilizes MYCN through a direct proteinprotein interaction, making MYCN less degradable by the proteasome [23]. AURKA mRNA expression has been described as a negative prognostic factor for neuroblastoma patients [24]. Therefore, AURKA has garnered much interest as a target in this disease [24]. On the other side, AURKB has been confirmed as a direct transcriptional target of MYCN, and its expression was observed increased in patients with poor outcomes [25]. Both kinases are therefore candidates for successful targeting with specific inhibitors. In fact, many preclinical studies have been conducted with anti-AURKA compounds. Among these compounds are orally active small-molecule inhibitors of AURKA (Fig. 1a), MLN8054 and MLN8237 (alisertib) [3, 26]. Both compounds have been tested in vitro and in vivo. However, of these two compounds, particular interest was given to MLN8237 due to its higher potency to inhibit AURKA, whereas dose-limiting toxicity was observed for MLN8054 [27, 28]. Nevertheless, the therapeutic promise of MLN8237 that was previously observed in vitro was not confirmed when tested in neuroblastoma patients, since it showed low efficacy, particularly in neuroblastoma patients with $M Y C N$ amplification [29].

An interesting screening approach for the evaluation of the most potent inhibitors of AURKA has been proposed at the preclinical level by Gustafson and colleagues [30]. Their principal aim was to select a candidate compound that would lead to the degradation of the MYCN protein. The authors wanted to create an AURKA inhibitor able to compromise protein conformation and hence perturb MYCN-AURKA interaction [23]. Starting from tozasertib as a chemical model, the authors selected the candidate CD532 as a strong inhibitor of AURKA, which fulfilled the desired function of MYCN protein destabilisation. Application of CD532 induced an inactive AURKA conformation that provoked loss of MYCN protein due to its degradation [31]. Tested in vitro or in vivo using a MYCN-amplified neuroblastoma xenograft model, CD532 showed remarkable features in eradicating MYCN protein, warranting its probable use against neuroblastoma in future therapies. We are expecting an optimised version of CD532, which will allow its application in clinical trials.

Another approach applicable to the therapy of neuroblastoma patients is targeting of both aurora kinases, using non-selective anti-aurora compounds. In fact, panaurora kinase inhibitors are a subject of interest of many researchers who believe in their potency as anti-tumour drugs. By affecting both Auroras, A and B, a more substantial impact on tumour cells might be expected. To date, the pan-aurora inhibitors CCT137690 [32] and tozasertib (VX-680, MK-0457) [33] have been tested. Each of them has been demonstrated as a potential drug for targeting drug-resistant neuroblastoma cells [34], which has made them interesting candidates for further clinical evaluation.

\section{Inhibitors of MYCN/MAX interaction}

As other members of the MYC family of proto-oncogenes, MYCN also works as a transcriptional activator. To fulfil this action, MYCN requires the formation of a heterodimer with the MAX protein [35]. This binding is necessary for proper activity of the MYCN protein; hence, its obstruction has been considered as a strategy through which MYCN can be targeted in tumours. For this purpose, several small molecules have been designed for MYC inhibition and have been proven as efficient blockers of MYCN/MAX interactions. Among them are the structurally unrelated compounds 10074-G5 and 10058F4 (Fig. 1a), which have been tested in vitro and which produce satisfying effects on neuronal differentiation and the induction of apoptosis [36]. Whether these compounds can repeat their effectiveness against neuroblastoma cells in vivo still remains to be verified.

\section{Bet inhibitors}

Another well-accepted approach for indirect MYCNtargeting is by inhibiting the BET (bromodomain and extra-terminal domain) family of proteins, which are important for transcriptional regulation of many genes including MYCN. One of the compounds developed for this purpose is the small molecule BET bromodomain 


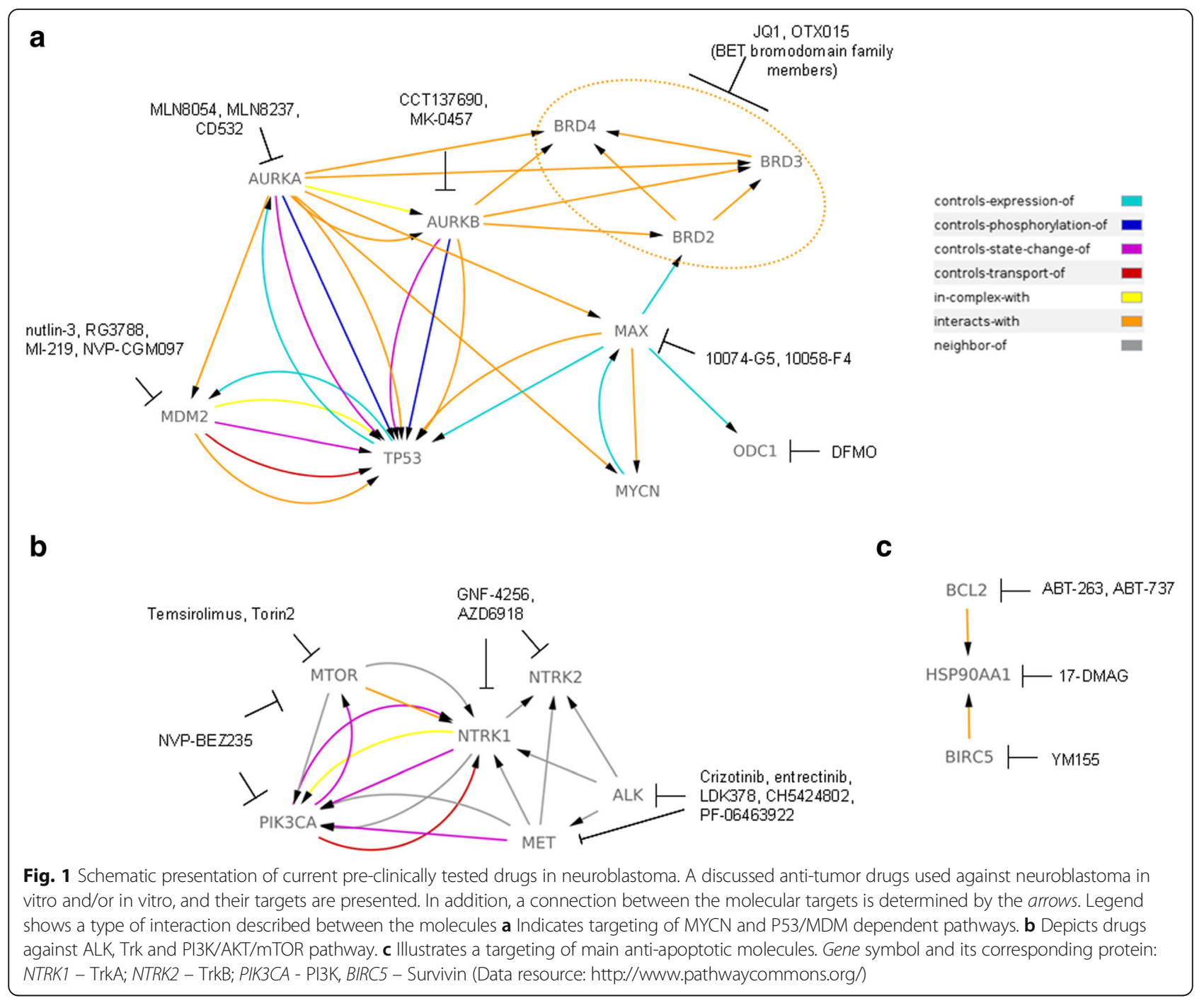

inhibitor JQ1. Puissant and colleagues [37] demonstrated the use of JQ1 as a promising strategy for blocking the growth of MYCN-dependent neuroblastoma cells in vitro. It has been confirmed that JQ1 has anti-tumour properties in vivo, suggesting that JQ1 might be an option for the treatment of MYCN-dependent neuroblastomas [38]. However, additional studies are necessary to confirm JQ1's effectiveness in the clinical setting. More recently, a European-American collaboration is applying BET inhibitors in neuroblastoma therapy [39]. In this study, Henssen et al. evaluated OTX015 as a promising anti-tumour drug in MYCN-driven neuroblastomas. In particular, OTX015 was shown to have a potent inhibitory effect on the growth of either mouse or human MYCN-dependent neuroblastomas. The mechanism of action involves the impediment of BRD4, one of the BET family proteins, to maintain active transcription of genes with super enhancers in their promoter regions. Interestingly, $M Y C N$ is among the genes that have super enhancers. Taken together, the data from the latter report suggest that OTX015 is a reasonable choice for targeted therapy of MYCN-amplified neuroblastomas.

\section{MYCN downstream pathway targeting}

It is possible that targeting of the proteins in the pathways downstream of MYCN might be also an useful and strategic alternative to direct inhibition of MYCN. There are several targetable candidates downstream of MYCN for which drugs are already available: MDM2 (by nutlin3 or RG3788) [40], ODC1 (by difluoromethylornithine -DFMO) [41] and mTOR (by Temsirolimus) [42].

P53/MDM2 targeting Unlike tumours in adults, which tend to overcome physiological regulation of P53 tumorsupressor by the means of mutations of TP53 gene, neuroblastoma is rarely associated with those mutations [43]. Nonetheless, the P53 pathway is often impaired in childhood cancers because of upstream P53/MDM2/ 
P14 ${ }^{\text {ARF }}$ network aberrations. Therefore, it is of great interest to understand the interaction between P53 and its main negative regulator MDM2, as it may lead towards a therapeutic approach in paediatric patients with malignancies that do not have TP53 mutations and who have poor prognoses [44]. In neuroblastoma, however, there is evidence that the P53 pathway is inactivated [45], and the inactivation of the P53 pathway occurs mainly at the time of relapse, probably contributing to chemoresistance. Several studies have confirmed that wild-type TP53 alleles exist in most cases of newly diagnosed neuroblastoma, but after chemotherapy, the P53/ MDM2/P14 ${ }^{\mathrm{ARF}}$ pathway is repressed, in part because of the abnormal inhibition of P53 by MDM2 [46-48]. This finding suggests that down-regulation of the P53 axis may underlie the treatment of patients who acquire drug resistance, which is a situation that is frequently observed in HR neuroblastoma. Although P53 is very rarely mutated in primary neuroblastoma at diagnosis and its downstream effectors are functional [47], multiple hits seem to cooperate to impair P53 functions, including deregulation of the ARF/MDM2 pathway [49, 50], expression of microRNAs that can target P53 pathways [51], and repression of P53-mediated autophagy [52]. Recent studies are focusing on current therapies and novel drugs targeting P53 signalling in neuroblastoma to understand the equilibrium between P53 family proteins and their regulation in neuroblastoma [53].

As so, a very frequent functional abnormalities detected in the P53/MDM2/p14 ${ }^{\mathrm{ARF}}$ pathway of relapsed patients shed light on its potential clinical targeting. One of the strategies to affect this pathway is by perturbing the P53/MDM2 interaction, in which MDM2 acts as a negative regulator of P53 levels [54]. Small molecules, such as nutlin-3 or MI-219, can interact with MDM2 by mimicking the P53 N-terminal region, where MDM2 binds to P53. Both of these small molecules have been tested in neuroblastoma, and the results of the studies showed that the effects depend on the MYCN status of neuroblastoma cells $[21,55]$. More precisely, it has been found that overexpression of MYCN sensitises neuroblastoma cells to the use of MDM inhibitors, confirming that MYCN and MDM2 together confer pro-survival benefits to tumour cells [56]. Regarding nutlin-3, it has been reported to work independently of P53, affecting other important pro-tumour molecules, such as P73 or multidrug resistance protein 1 (MDR-1), that are responsible for drug resistance in different types of cancer [57]. Tests of MDM2-P53 antagonists are ongoing in several clinical trials in which these antagonists are administered either alone or in combination with other anti-cancer drugs [58]. We will have to wait and see the outcome of these trials to draw a conclusion about the promise of these inhibitors for use in personalised targeting. Until then, a strategy that might be adopted for the selection of the patients who might benefit from treatment with these compounds was suggested by Jeay et al. [59]. The authors described a gene signature that enables rapid prediction of tumours sensitive to NVP-CGM097, a potent and selective MDM2 inhibitor [60]. The same approach could be used for the recruitment of neuroblastoma patients for whom inhibition of P53/MDM2 might be highly effective.

ODC1 Encodes for ornithine decarboxylase 1, an enzyme required for synthesis of polyamines. The level of this enzyme is increased in highly metabolically active cells, such are the normal growing cells, but also transformed neuroblasts. In fact, the $M Y C N$-driven neuroblastomas promote polyamine production by coordinating its downstream targets among which $O D C 1$ [61]. Therefore, a targeting of polyamine metabolism in $M Y C N$-positive neuroblastoma has been considered preclinically and also during clinical trials [61, 62]. The efficiency of an irreversible inhibitor of the ODC1, known as difluoromethylornithine (DFMO; Eflornithine), drew a particular attention of oncologists [63]. It has been confirmed that the preemptive block of polyamine production by DFMO could impair tumour growth either in vitro or in the in vivo $\mathrm{MYCN}$-mouse model [64]. These findings support not only the relevance of MYCN for the synthesis of polyamines, but also imply that depletion of this metabolic route might be a successfully alternative to direct MYCN targeting in neuroblastoma patients. In the moment, DFMO is tested either alone or together with other chemotherapics (NCT02395666, NCT01586260 and NCT01059071 - Table 1) and results of clinical trials are expecting.

mTOR Mammalian target of rapamycin plays an essential function in cells' growth regulation and protein production control [65]. Targeting of mTOR is very attractive since its block leads to MYCN destabilization, unfavouring therefore neuroblastoma growth [66]. However, since mTOR signals downstream from PI3K/AKT pathway, its targeting will be discussed together with drugs against this signalling branch.

\section{Inhibitors of anaplastic lymphoma kinase (ALK)}

ALK is a receptor tyrosine kinase (RTK) implicated in the development of neuroblastoma [67-69]. As discussed previously [70], activating mutations in the $A L K$ gene have been described in either familial neuroblastoma (under $1 \%$ ) or in sporadic disease (approximately $8 \%$ ) [71, 72]. Additionally, ALK has been confirmed as a target of the MYCN transcription factor, which automatically links this molecular marker with a poor outcome in neuroblastoma patients. Therefore, it is not surprising that retinoic acid 
can down-regulate the expression of the $A L K$ gene as well, as a direct consequence of $M Y C N$ down-regulation [73]. Scientists interested in ALK share a strong confidence in its targeting during anti-neuroblastoma treatment. In fact, many of them believe that inhibition of ALK could ensure improved outcomes for neuroblastoma patients. Therefore, many strategies have been adopted in blocking the constitutive activation of ALK [74]. Because ALK is a cellmembrane receptor, its use in antibody-targeted therapy has been considered. This possibility was tested by the use of antibodies that block conformational activation of the tyrosine kinase domain after dimerization of two nearby ALK receptors [75]. However, this approach showed certain limitations, which might be improved by combining ALK-targeted immunotherapy with next-generation ALK inhibitors that act intracellularly [76].

\section{Novel ALK inhibitors}

A new generation of anti-ALK compounds inhibit kinase activity of this RTK. These compounds recognize and bind to the adenosine triphosphate (ATP) pocket of the receptor. Thus, the compounds compete with ATP, thereby preventing subsequent autophosphorylation, which is necessary for further signal transduction. Many ALK inhibitors have been tested either preclinical or clinically with a wide range of effectiveness. The most known anti-ALK drug is crizotinib (Pfizer; Fig. 1b), which gave promising results during treatment of patients with deregulated ALK function [77, 78]. This drug is a small molecule inhibitor capable of targeting ALK, ROS1 and MET RTKs. In vitro studies demonstrated that crizotinib is particularly efficient in neuroblastoma cells with the R1275Q mutation. Hence, crizotinib might be a valuable choice for the treatment of neuroblastoma patients with either amplifications or mutations in the $A L K$ gene [79]. One point of caution is that we might need to use crizotinib in combination with other drugs in order to prevent resistance phenomena [80]. This hypothesis is in line with recent results published by Krytska and colleagues [81], who confirmed that when used in combination with the current chemotherapeutic agents topotecan and cyclophosphamide, crizotinib exhibited increased cytotoxic effects. Interestingly, deep sequencing has been shown to be an efficient approach for quick detection of $A L K$ mutations within tumour biopsies responsible for resistance to crizotinib [82]. This technique might be useful for follow-up assessments of treatment efficacy by allowing the detection of possible resistance long before it actually develops. Another newly proposed ALK inhibitor is entrectinib (Ignyta Inc) which is currently being tested in a clinical trial (NCT02097810 - Table 1) [83]. This drug showed excellent cytotoxic effects in vitro, particularly in neuroblastoma cells with amplified $A L K$ [84]. Additionally, the activity of entrectinib against neuroblastoma cells bearing $A L K$ mutations was significantly improved when this drug was combined with chloroquine. This proposed combination was justified by the findings that application of entrectinib induced autophagy that protected tumour cells from death. In this work, a similar behaviour was observed for crizotinib, which induced autophagy in neuroblastoma cells when tested under the same in vitro conditions. Besides affecting ALK, entrectinib was also confirmed as an effective and promising compound against TrkBdependent neuroblastomas, supporting the initiation of a phase 1 clinical trial for this compound in neuroblastoma patients with refractory disease [85]. In this case, the effectiveness of entrectinib in inhibiting neuroblastoma growth in vivo was determined after either single use of this compound or after its combination with the conventional chemotherapeutic drugs irinotecan and temozolomide. Given the frequency of $A L K$ gene deregulation in neuroblastoma patients, it is reasonable to expect that many pharmaceutical companies will search for secondgeneration ALK inhibitors, possibly with more specificity for $A L K$ mutations. Some of these inhibitors are in preclinical or clinical phases for neuroblastomas, such as LDK378 (ceritinib; Novartis Pharmaceuticals; NCT017 42286 - Table 1) [69] and Alectinib (CH5424802; Alecensa; NCT01871805 - Table 1) [86].

A serious issue that remains is whether mentioned antiALK compounds would lead to the development of resistance, which was observed for crizotinib [87]. However, this seems not to be the case for PF-06463922, a potent and selective next-generation ROS1/ALK inhibitor tested by Infarinato et al. [88]. The authors described PF06463922 as an extremely efficient drug when used for the treatment of neuroblastoma in crizotinib-resistant xenograft mice. The compound not only showed a potential to overcome crizotinib resistance but also a high capacity to induce complete tumour regression when administered alone in vivo. It should be emphasized that quicker detection of $A L K$ mutations within tumour biopsies responsible for resistance to crizotinib would be necessary. Numerous ongoing investigations into the effectiveness of anti-ALK therapeutics provide confidence that we will soon be closer to a cure of HR neuroblastoma with deregulated ALK RTK.

\section{TrkA and TrkB: different roles in neuroblastoma}

A line of evidence suggests that the TRK family of neurotrophin receptors plays a critical role in the diverse courses of neuroblastoma development. Human TrkA gene maps to 1q21, but no mutations or activating rearrangements have been identified in neuroblastoma [89]. Neuroblastomas are biologically favourable and susceptible to spontaneous regression or differentiation 
when TrkA is expressed. In this case, neuroblastoma fate depends greatly on the absence or presence of the TrkA ligand, nerve growth factor (NGF). In most tumours of patients in advanced stages, TrkA expression is low or absent, and such tumours do not undergo complete differentiation in response to NGF. This indicates that the NGF/TrkA pathway is responsible for differentiation and regression of favourable neuroblastomas. Another human Trk, TrkB, was cloned and mapped to $9 \mathrm{q} 22$ [90], and similarly, no mutations or activating rearrangements for this gene have been found in neuroblastomas to date. The TrkB receptor and its ligand are highly expressed in biologically unfavourable neuroblastomas. Full-length $\operatorname{Trk} B$ and $B D N F$ are expressed in more aggressive neuroblastomas, and their expression is highly correlated with $M Y C N$ amplification [91]. In addition, it has been shown that TrkB expression in neuroblastomas is associated with drug resistance and expression of angiogenic factors [92]. Thus, the expression of both BDNF and full-length TrkB may represent an autocrine or paracrine survival pathway that is important for the aggressive behaviour of some neuroblastomas [93, 94]. Because TrkB has been correlated with poor outcome of neuroblastoma patients [95], its targeting in neuroblastoma is reasonable. GNF-4256, a selective and potent pan-Trk inhibitor (Novartis; Fig. 1b), is one of the compounds designed to target TrkB. This inhibitor demonstrated potent cytotoxic effects, both in vitro and in a mouse xenograft model [96], when used alone or in combination with irinotecan and temozolomide. These results suggest that GNF-4256 is an attractive compound for the therapy of relapsed neuroblastoma patients with dysregulated TrkB. Moreover, preclinical studies confirmed its low toxicity. Promising anti-tumour activity was also reported for AZD6918, a recently proposed novel pan-Trk inhibitor, that was tested in vivo [97]. Similarly to GNF-4256, AZD6918 showed strong inhibitory effects on tumour growth when used in combination with other conventional chemotherapeutics, such as etoposide. These results suggest that Trk (TrkB preferentially) inhibitors might be effective in personalised therapies for neuroblastoma patients with deregulated TrkB activity. A more detailed study in this field was performed by Nakamura et al. [98], who tested a series of synthetic candidate compounds predicted to have anti-TrkB activity in silico. These compounds were then analysed in vitro and in vivo to evaluate their efficiency against neuroblastoma tumour growth. The most efficient compounds identified in this study were suggested as drugs against TrkB-dependent neuroblastomas. Whether they might repeat their effectiveness in preclinical studies remains to be validated.

\section{Drugs against the PI3K/AKT/mTOR pathway}

A recent study showed that the persistence of $A L K$ mutations, and hence its constitutive activation, led to over-activation of several downstream signalling pathway, including PI3K/AKT/mTOR, in a subset of neuroblastoma [80]. Berry et al. showed that co-expression of one of the most common $A L K$ mutations $\left(A L K^{F 1174 L}\right)$ and MYCN amplification up-regulated several down-stream pathways, including the PI3K/AKT/mTOR pathway, in a neuroblastoma mouse model. In addition to ALK, several other RTKs and/or their ligands have been implicated in the increased activation of the PI3K/AKT/mTOR pathway in neuroblastoma [99]. However, although there is increasing evidence supporting a role of the PI3K/AKT/ mTOR pathway in the development and progression of neuroblastoma, the molecular mechanisms that actually activate the PI3K/AKT/mTOR remain to be elucidated.

Certainly, it is to be expected that by blocking a part of this pathway, the proliferative capacities of neuroblastoma tumour cells should be inhibited. Still, the most relevant question that remains to be answered is where is the Achilles heel of this signalling cascade in tumour cells and where should we strike? Numerous inhibitors have already been developed, and some of them have been tested in neuroblastoma [100]. Because PI3K/ AKT/mTOR pathway inhibitors have been discussed in many reviews already, e.g., Pal et al. [101], Mei et al. [102], we will focus only on the therapeutic aspects of the latest scientific reports.

A strategy involving the blockade of mTOR's function to ameliorate ALK inhibition itself has been proposed by Moore and colleagues [87]. The authors observed that ALK inhibition by crizotinib did not affect all branches of the downstream pathways of ALK, leaving the mTOR-dependent signalling pathway active. The important relationship between ALK and the PI3K/AKT/ mTOR pathway has also been illustrated by the finding that combined treatment with the ATP-competitive mTOR inhibitor Torin2 overcame the resistance of $A L K^{F 1174 L} / M Y C N$ tumours to crizotinib. In the same work [87], the authors combined crizotinib with mTOR inhibitors. This combination led to a strong cell cycle arrest and, importantly, prevented the growth of neuroblastoma tumours, suggesting that multiple attacks of ALK downstream pathways might be necessary for efficient defeat of tumour. Westhoff et al. [103] proposed similar experiments to improve effectiveness against neuroblastoma by using NVP-BEZ235, a PI3K/mTOR inhibitor (Fig. 1b), together with conventional chemotherapeutics. However, we must exercise caution in planning strategies against PI3K in the battle against neuroblastoma. As explained by Westhoff and colleagues [103], we must consider proposed drug use critically, keeping in mind that usually "there is no linear link 
between degree of inhibition that we provoke chemically and inhibition of tumour growth". On the other hand, numerous studies have proposed the combined targeting of AKT with various biological agents as a more successful approach. There is a clinical trial (NCT01049841 Table 1) ongoing for perifosine, which is one of the bestcharacterized AKT inhibitors, in combination with the mTOR inhibitor temsirolimus. It is expected that this combination would provide a better impact on tumour growth, ensuring a synergic effect between these drugs that has been observed in previous preclinical studies [104]. This therapeutic choice can be additionally justified by the results obtained from the clinical studies in which temsirolimus, used as mono-therapy, worked as cytostatic and guaranteed a stable disease after 12 weeks of treatment [105]. At the moment some clinical trials are recruiting patients to test temsirolimus in combination with standard chemotherapy and monoclonal antbodies, in order to seek for more promising cure of neuroblastoma patients with deregulated PI3K/AKT/ mTOR signalling (NCT01767194 - Table 1). Whether neuroblastoma patients would benefit from these therapy remains to be seen.

\section{Drugs against the anti-apoptotic molecules - Survivin, BCL2 and HSP90}

Survivin is another molecular biomarker whose enhanced expression was correlated with poor prognosis in neuroblastoma patients [106]. Encoded by the gene BIRC5, this protein has anti-apoptotic activity and represents an interesting druggable target whose blockage might provide significant benefits to HR neuroblastoma patients $[107,108]$. Therefore, this candidate is an attractive target in neuroblastoma, even though its eventual integration in currently used therapy has not been considered profoundly. One of the compounds that regulates Survivin expression and hence its cell death-protective role is YM155 (Fig. 1c) [109]. The most important fact is that YM155 shows efficacy in eliminating tumour cells with acquired resistance to doxorubicin, vincristine and cisplatin. These findings imply that Survivin depletion could assure benefits to the patients in whom standard therapy has limited effects.

BCL2 is a protein with an important role in cell surviving $[110,111]$. Although $B C L 2$ mutations are rare in neuroblastoma, this pro-survival protein plays an important function in neuroblastoma due to its deregulated expression $[112,113]$. In fact, expression profiling studies have confirmed the increased levels of $B C L 2$ gene in many neuroblastomas. Therefore, BCL2 likely represents a good molecular target for neuroblastoma treatment. Several anti-BCL2 drugs have been designed to date (among which is a BH3 mimetic), such as ABT-263 and ABT-737, which appear to be particularly promising and efficient [114]. Nevertheless, the effect of the aforementioned inhibitors in neuroblastoma is still to be investigated sufficiently.

Recently, much attention has been paid to the inhibition of Heat shock protein 90 (Hsp90) as a strategy for neuroblastoma treatment. As a central molecule of complex folding machinery, HSP90 acts as a major regulator of protein integrity and function for the vast majority of proteins, including those with oncogenic potential [115]. High expression of HSP90 ensures protection from degradation for numerous proteins inside the cell, including ERBB2, AKT, MET and MYCN. Hence, over-expression of HSP90 protein in malignancies has been described as an anti-apoptotic feature, and its abrogation is seen as a therapeutic option even in neuroblastoma [116]. A role of HSP90 in protecting MYCN from degradation was observed when 17-DMAG (Alvespimycin), a small inhibitor against HSP90, was used in vitro. Interestingly, the same treatment also decreased the expression of AKT [117]. Another intriguing approach for targeting HSP90 in neuroblastoma has been proposed by Sidarovich et al. [118]. The authors discovered the potential to suppress the translational efficiency of heat shock proteins, including HSP90, by using compounds with iron-chelating characteristics. As a result, the authors observed a significantly reduced growth of neuroblastoma in a cell culture system. However, it is clear that additional work and clinical trials are necessary to evaluate whether the anti-apoptotic drugs can be a valuable clinical tool. In summary, although positive results from the preclinical testing of drugs against anti-apoptotic proteins have been obtained, it still remains to be seen if these drugs will be employed clinically as therapeutic strategies for the treatment of neuroblastoma.

\section{Current views and directions in neuroblastoma therapy: the Omics as the basis for personalised medicine}

Among all Omics, the advent of massive parallel sequencing approach, so-called Next Generation Sequencing (NGS), has enabled a more detailed and deeper molecular characterisation of the neuroblastoma tumours. The analysis of the entire genome and exome showed genomic alterations associated with the molecular pathogenesis of neuroblastoma [119-124]. In particular, somatic point mutations and somatic structural variants in the PTPRD, ODZ3, CSMD1 and ARID1A genes $[120,123]$, a few high-frequency recurrent somatic mutations in the ALK, CHD9, PTK2, NAV3, NAV1, FZD1, ATRX, ARID1B, TIAM1, ALK, PTPN11, OR5T1, PDE6G, $M Y C N$ and NRAS genes [119, 120, 122, 123] and rearrangements in TERT gene super enhancer region $[121,124]$ are discovered in neuroblastoma patients with worst survival. 
Considering all currently available genomic data, several national and international groups operating in neuroblastoma field discussed in March 2015 during the SIOPEN Genomics Meeting in London, a NGS neuroblastoma signature for tumours of HR patients. At this meeting the collaborators proposed a panel of mutations, determined by whole exome sequencing (WES), to be screened in neuroblastoma patients, defining in that way a NGS signature specific for neuroblastoma [70]. The use of NGS profile is the first step towards personalised medicine in this paediatric malignancy. Subsequently, genomic data assisted in the development of pharmacogenomic technologies that allow the determination of specific therapeutic approaches for genetically homogenous cohorts of patients. It is expected that the current therapeutic protocol adopted for patients of one risk group will be replaced by a specific drug combination designed to treat patients based on their specific genetic profiles. A pioneer result that compare mutational spectrum in mitochondria $(\mathrm{mt})$ versus nuclear (n) DNA in neuroblastoma patients at diagnosis and at relapse has been published by Reihl et al. [125]. To address the question if and in which extent DNA appertaining to these two cell compartments varies at spatiotemporal scale they applied WES. They found that both mtDNA and nDNA showed similar variations in relapsed samples with respect to samples obtained at diagnosis. Hence, the authors suggest that observed genetic variances could be useful biomarkers for monitoring of neuroblastoma progression. In support to this concept, recent studies on matched primary tumours and biopsies at relapse clarified that genetic alteration in CHD5, DOCK8, PTPN14, HRAS and KRAS genes and losses on chromosome $9 \mathrm{p}$ acquired during tumour progression suggesting a likely tailored therapy against these genetic alterations in patients at the disease recurrence [126]. Furthermore, the authors showed that the overall count of mutations in biopsies at relapse is higher than in primary tumours. In another independent, non-overlapping study, $78 \%$ of recurrent tumours harboured a higher overall mutations count compared to primary tumours showing an hyperactivated RAS-MAPK signalling pathway [127]. Both reports introduced the concept of temporal and dynamic cancer model in which neuroblastoma primary tumours were composed of a minor population of multiple clones that persisted throughout the therapy, expanding then at the recurrence [128]. Together, these studies suggest that the analysis of recurrent tumour biopsies is mandatory for any clinical trial [128].

\section{Metabolomics and proteomics - is it time to move therapy towards precision medicine?}

Additional Omics that will certainly contribute to more effective personalised medicine are metabolomics and proteomics. The analysis of small-molecule metabolites is an advantageous means to differentiate normal from malignant tissue and to predict tumour treatment response [129-131]. Indeed, Imperiale and colleagues [132] defined a metabolite profile using tumour of neuroblastoma patients, establishing differences in their profiles with respect to healthy tissues. More precisely, they defined the so-called metabolic fingerprint of neuroblastoma as a metabolic marker to control the disease course. Another valuable approach includes metabolome analysis of patients' sera to improve the reliability of diagnosis or riskstratification of neuroblastoma patients, as reported by Beaudry et al. [133]. The authors performed a retrospective metabolome study, examining whether the patient's sera discriminate low from HR neuroblastoma patients. They observed equally distributed metabolite profile between low and HR patients using nuclear magnetic resonance (NMR). In addition, they analysed metabolites profile in sera of mice after neuroblastoma xenografts by NMR and gas chromatography-mass spectrometry. Importantly, they distinguished the metabolites differentially present at early phase versus late stage of disease proposing them as possible biomarkers to determine a presence of early stage tumours. Moreover, the results of these analyses done in humans and repeated using sera of xenografted-mice gave comparable profiles confirming that the xenografts recapitulate the behaviour of human tumours. These observations imply that the analysis of metabolome profile from neuroblastoma patients' sera, together with other diagnostic tools already used in clinic, could enable more accurate prediction of tumour behaviour. In any case, at this moment larger studies are needed to determine whether identification of key metabolites in patients' sera can be used as diagnostic tools in neuroblastoma. As far as proteomics is concerned, the level of specific protein biomarkers in the plasma of neuroblastoma patients can determine HR neuroblastoma [134]. These results support the integration of proteomic approaches as fast and non-invasive techniques in the monitoring of neuroblastoma behaviour in HR patients. Additional findings that provide evidence in favour of metabolic markers have been provided by Otake et al. [135], who defined new biomarkers of an unfavourable neuroblastoma phenotype, applying shotgun proteomic analysis. The authors focused particular attention to the protein DDX39A, which might be considered a novel marker for proteomics approaches to HR neuroblastoma diagnosis. Several in vitro validation studies also gave encouraging data that a proteomic approach can be applied to define the diverse intracellular pathways and molecules that are responsible for: i) an aggressive neuroblastoma phenotype or ii) resistance to therapy $[136,137]$. 


\section{High-throughput drug screening}

The National Cancer Institute has launched a program to assess new drugs for paediatric use, called the Paediatric Preclinical Testing Program (PPTP) [138]. The PPTP is an initiative to identify therapeutic drugs that have significant activity against childhood cancers, including neuroblastoma. The PPTP has established panels of childhood cancer cell lines and xenografts to be used for in vitro and in vivo testing. The PPTP has the capacity to test approximately 12 compounds or combinations of compounds in preclinical models of childhood cancers. The cancers include Wilms tumour, sarcomas (rhabdomyosarcoma, Ewing sarcoma and osteosarcoma), neuroblastoma, brain tumours (glioblastoma, ependymoma and medulloblastoma), rhabdoid tumours (CNS and renal) and acute lymphoblastic leukaemia (ALL). The selection of drugs for PPTP testing is based on their potential relevance in the childhood cancer setting and their stage of clinical development. In parallel, standard drugs are also being tested, both to calibrate the PPTP tumour panels and to serve as a basis for future combination studies [107]. Between 2008 and 2015, more than 60 reports of initial testing (Stage 1) were published by the PTPP. From the point of the in vitro studies, another interesting approach arrives and proposes high-throughput screening for the best single or combined drug selection. In fact, an increasing number of reports identified high-throughput screening as useful methodology to select additional functional antitumour drugs. Indeed, an example is the screening of compounds against the neuroblastoma cell line IMR32, from which it was discovered that the $P H O X 2 B$ gene might be targetable by influencing its direct transcriptional regulators, such as Meis-1, NF- $\mathrm{kB}$ and AP-1 [139]. Accurate evaluations of high-throughput screening in neuroblastoma have been described by Harder et al. [140]. Therefore, we propose that introducing this technique could lead to increased identification of promising compounds for neuroblastoma treatment. The identification of new compounds could allow us to increase the number of clinical trials for personalised medicine.

\section{Epigenetic biomarkers and regulatory RNAs}

Recently, analysis of epigenome profiling and microRNA (miRNA) expression patterns performed in neuroblastoma samples has provided a significant amount of data, identifying the targeting of epigenetic regulators as a possible treatment strategy. It is also expected that epigenomic studies will identify new biomolecular markers that may lead to a better stratification of neuroblastoma patients.

\section{Epigenetic background of neuroblastoma}

Aberrant DNA methylation, either hyper- or hypomethylation, has emerged as a new hallmark of tumourigenic processes [141]. In particular, changes of the "physiological" methylation patterns have been correlated with neuroblastoma patients' prognosis [142]. Additional studies of DNA methylation profiles in neuroblastoma tumours have identified the pro-apoptotic gene CASPASE 8 and the tumour suppressor gene RASSF1A as novel target molecules. The hyper-methylation of their promoter regions, and hence reduced or absent gene expression, has been confirmed in the majority of examined neuroblastoma [143]. Soledad Gómez and colleagues revealed that major DNA methylation changes took place outside promoter regions. More importantly, they observed that the changes in the methylation pattern are associated with clinico-pathological characteristics of neuroblastoma [144]. A similar conclusion was drawn by Buckley et al. [145], who associated a hyper-methylation pattern with diverse neuroblastoma phenotypes.

\section{Non coding RNAs}

Another class of biological molecules whose expression depends on epigenetic regulators are microRNAs (miRNAs). As non-coding RNA molecules, miRNAs are able to control the expression of genes at the post-transcriptional level. miRNAs have emerged as very important biomarkers of many cancers including neuroblastoma. In fact, an increasing number of studies indicate that imbalanced expression of miRNAs could offer an alternative explanation for neuroblastoma aggressiveness and serve as a basis for selection of more efficient drug combination [146]. Even at this level MYCN is an important player, since some miRNAs are described as direct transcription targets of MYCN. Among them, several miRNAs with tumoursuppressor features (e.g. miR-184, miR-181a-5p, miR181b-5p, miR-320a) [147] are evidenced. These findings suggest that MYCN, beside direct impact on its target genes, can indirectly regulate a subset of other genes at post-transcriptional level. There are several data that indicate that miRNAs profiles are predictive for the outcome of neuroblastoma patients [148-150]. Some of the suggested miRNAs might be interesting targets to be combined with standard therapeutic protocols for neuroblastoma cure in future. High throughput studies of long non-coding RNAs (lncRNAs) also highlighted the role of these regulatory RNAs as promising drug targets for therapeutic interventions. Indeed, a recent sequencing transcriptomes analysis of low- and HR neuroblastomas pinpointed a lncRNA neuroblastoma associated transcript-1 (NBAT-1) as a biomarker that predicted neuroblastoma patients outcome [151]. The authors showed that NBAT-1 was necessary for differentiation of neuronal precursors and that hypermethylation of its promoter region and following gene down-regulation increases neuroblastoma cells proliferation. Being described as tumour suppressor, NBAT-1 might be among crucial 


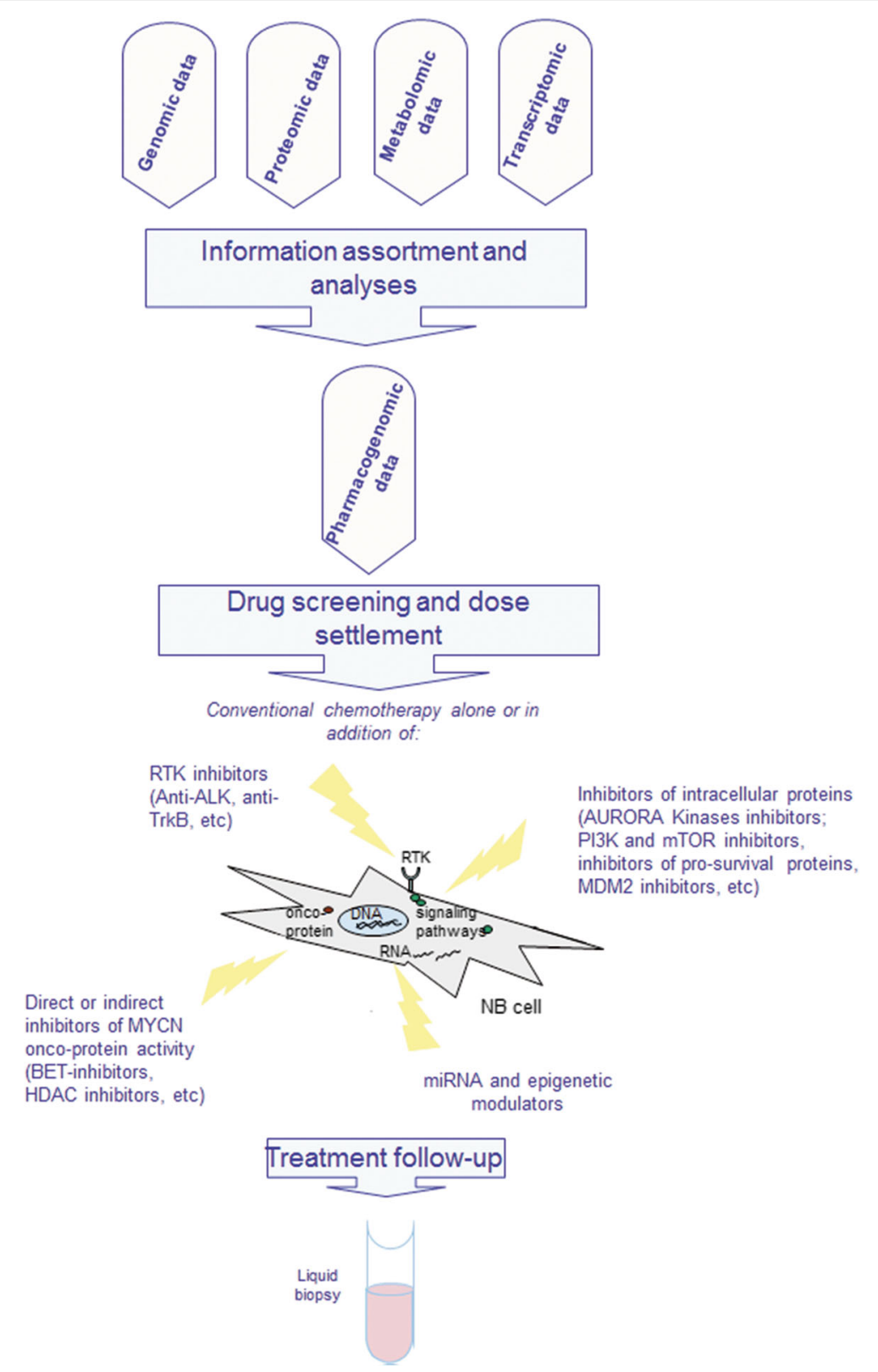

Fig. 2 Flow chart of Omics data integration for personalised treatment. At the top of the figure, schematic presentation of Omics data processing, the assortment and analyses is shown. Once collected, omic technologies data obtained by studying tumor material or CTC from blood, have to be integrated to allow the extraction and selection of the druggable single target or molecular pathways. This step proceeds by the screening of the most reliable drug or drug combination that would assure optimal chances for tumour defeating. Some of the compounds are listed in the figure: MYCN, ALK, AURORA A, TrkB. In the lower part of the figure is shown the liquid biopsy as a procedure to use at the follow-up in order to understand how disease behaves due to treatment. In the case of neuroblastoma, integration of liquid biopsy for the follow-up of molecular biomarkers during therapy might be a winning strategy for early detection of possible drug resistance that could allow clinicians to change current therapeutic strategy

regulatory RNAs and so, the therapy against NBAT-1 and its downstream effectors could be a potential novel therapeutic option for the treatment of HR neuroblastoma [151]. Moreover, another recent study evaluated differential expression profiles of lncRNAs and protein-coding genes between $M Y C N$ amplified and non-amplified neuroblastomas by examining microarray and RNA-seq datasets [152]. The authors revealed correlation between SNHG1 regulation and $M Y C N$ amplification and suggested SNHG1 as another indicator of neuroblastoma patient's outcome and/or as an option for therapeutic targeting. 


\section{Liquid biopsy as a useful technique for Omics studies}

In recent years, liquid biopsy has been used as a biological sample that enables diagnosis and monitoring of disease status. Blood liquid biopsy contains circulating tumour cells, which can be studied by Omics technologies. In neuroblastoma, liquid biopsy is very useful, particularly if tumour cells are not available from the primary tumour or are not sufficient for genomic studies. The importance of liquid biopsy for tumour studies was realised when it is discovered that the levels of cell-free circulating DNA (ctDNA; small, double-stranded fragments of DNA) in the blood were much higher in patients with cancer than in those of healthy individuals. These findings provide a basis for the possibility of using liquid biopsy to monitor the disease in a simpler and faster way [153]. In neuroblastoma, liquid biopsy is useful in evaluating $A L K$ and PHOX $2 B$ mutations, $M Y C N$ expression etc. As far as neuroblastoma is concerned, some research groups have already begun testing whether liquid biopsy could mirror the genetic profile obtained directly from tumours $[154,155]$. The first data obtained by the use of liquid biopsy at neuroblastoma diagnosis are promising. They suggest that this non-invasive approach could serve as a detection method of neuroblastoma at early time points of disease, allowing an immediate and suitable treatment. Liquid biopsy is also useful for the evaluation of the response to therapy by allowing for more frequent follow-up measurements of specific molecular markers persisting in liquid biopsies. A diagram of the workflow of liquid biopsy use in neuroblastoma and its integration with Omics technologies is shown in Fig. 2. Because the clinical utility of this approach has been already demonstrated for other types of cancer [156], its use in neuroblastoma provides new prospects for more accurate and faster diagnosis of the disease and eventual determination of the correct approach in personalised therapy.

\section{Conclusions}

In this review we provided an update of the pharmacological achievements proposed for neuroblastoma treatment during the last years. Moreover, we discussed the way that neuroblastoma management could be influenced by the findings obtained from Omics technologies. We also reported the importance of high-throughput Omics data for better risk's stratification of the neuroblastoma patients in order to provide a more efficient targeted therapy. From these techniques, it is expected to allow, in a rapid and strict way, a generation of the list of possible druggable targets that clinicians should consider to improve patients health. Indeed, these techniques will lead to the increased number of successful clinical trials which will contribute to increasing cure rates of neuroblastoma patients.

In conclusion, we believe that the use and integration of Omics data within other clinical and biological information already defined for neuroblastoma is the right direction toward precision medicine. Under this scenario, the Omics profiles should allow a more accurate characterisation of neuroblastoma phenotype providing a support for an efficient therapy against this pediatric tumor.

\section{Acknowledgements \\ The authors would like to thank Dr Carlo Zanon for helping with the figure preparation.}

\section{Funding}

The present work was supported by Fondazione Italiana per la Lotta al Neuroblastoma.

\section{Availability of data and materials}

All data generated or analysed during this study are included in this published article.

\section{Authors' contributions}

MRE, SA, AS have contributed to the design and preparation of the manuscript. GPT has contributed to the study for important intellectual content. MRE and GPT was also involved in the manuscript drafting and revising. All authors read and approved the final manuscript.

\section{Competing interests}

The authors declare that they have no competing interests.

\section{Consent for publication}

Not applicable.

Ethics approval and consent to participate

Not applicable.

\section{Author details}

'Paediatric Research Institute, Fondazione Città della Speranza, Neuroblastoma Laboratory, Corso Stati Uniti, 4, Padua 35127, Italy.

${ }^{2}$ Department of Biology, University of Padua, Padua, Italy.

Received: 28 September 2016 Accepted: 31 January 2017

Published online: 08 February 2017

\section{References}

1. Luksch R, Castellani MR, Collini P, De Bernardi B, Conte M, Gambini C, Gandola L, Garaventa A, Biasoni D, Podda M, et al. Neuroblastoma (Peripheral neuroblastic tumours). Crit Rev Oncol Hematol. 2016;107:163-81.

2. Shimada H. Tumors of the neuroblastoma group. Pathology (Phila). 1993;2:43-59.

3. Maris JM. Recent advances in neuroblastoma. N Engl J Med. 2010;362:2202-11.

4. Shimada H, Ambros IM, Dehner LP, Hata J, Joshi W, Roald B, Stram DO, Gerbing RB, Lukens JN, Matthay KK, Castleberry RP. The international neuroblastoma pathology classification (the Shimada system). Cancer. 1999:86:364-72

5. Maris JM, Hogarty MD, Bagatell R, Cohn SL. Neuroblastoma. Lancet. 2007; 369:2106-20.

6. Yu AL, Gilman AL, Ozkaynak MF, London WB, Kreissman SG, Chen HX, Smith M, Anderson B, Villablanca JG, Matthay KK, et al. Anti-GD2 antibody with GM-CSF, interleukin-2, and isotretinoin for neuroblastoma. N Engl J Med. 2010;363:1324-34.

7. Dobrenkov K, Cheung NK. GD2-targeted immunotherapy and radioimmunotherapy. Semin Oncol. 2014;41:589-612.

8. Heczey A, Louis CU. Advances in chimeric antigen receptor immunotherapy for neuroblastoma. Discov Med. 2013;16:287-94.

9. Chan HS, Gallie BL, Deboer G, Haddad G, Ikegaki N, Dimitroulakos J, Yeger $\mathrm{H}$, Ling V. MYCN protein expression as a predictor of neuroblastoma prognosis. Clin Cancer Res. 1997;3:1699-706. 
10. Kohl NE, Kanda N, Schreck RR, Bruns G, Latt SA, Gilbert F, Alt FW. Transposition and amplification of oncogene-related sequences in human neuroblastomas. Cell. 1983;35:359-67.

11. Schwab M, Alitalo K, Klempnauer KH, Varmus HE, Bishop JM, Gilbert F, Brodeur G, Goldstein M, Trent J. Amplified DNA with limited homology to myc cellular oncogene is shared by human neuroblastoma cell lines and a neuroblastoma tumour. Nature. 1983;305:245-8.

12. Tonini GP, Nakagawara A, Berthold F. Towards a turning point of neuroblastoma therapy. Cancer Lett. 2012;326:128-34.

13. Prochownik EV, Vogt PK. Therapeutic targeting of Myc. Genes Cancer. 2010;1:650-9.

14. Bell E, Chen L, Liu T, Marshall GM, Lunec J, Tweddle DA. MYCN oncoprotein targets and their therapeutic potential. Cancer Lett. 2010;293:144-57.

15. Thiele CJ, Reynolds CP, Israel MA. Decreased expression of N-myc precedes retinoic acid-induced morphological differentiation of human neuroblastoma. Nature. 1985;313:404-6.

16. Cinatl Jr J, Kotchetkov R, Blaheta R, Driever PH, Vogel JU, Cinatl J. Induction of differentiation and suppression of malignant phenotype of human neuroblastoma BE (2)-C cells by valproic acid: enhancement by combination with interferon-alpha. Int J Oncol. 2002;20:97-106.

17. de Ruijter AJ, Kemp S, Kramer G, Meinsma RJ, Kaufmann JO, Caron HN, van Kuilenburg AB. The novel histone deacetylase inhibitor BL1521 inhibits proliferation and induces apoptosis in neuroblastoma cells. Biochem Pharmacol. 2004;68:1279-88.

18. Chesler L, Schlieve C, Goldenberg DD, Kenney A, Kim G, Mcmillan A, Matthay KK, Rowitch D, Weiss WA. Inhibition of phosphatidylinositol 3-kinase destabilizes Mycn protein and blocks malignant progression in neuroblastoma. Cancer Res. 2006:66:8139-46.

19. Johnsen Jl, Segerstrom L, Orrego A, Elfman L, Henriksson M, Kagedal B, Eksborg S, Sveinbjornsson B, Kogner P. Inhibitors of mammalian target of rapamycin downregulate MYCN protein expression and inhibit neuroblastoma growth in vitro and in vivo. Oncogene. 2008;27:2910-22.

20. Cheung L, Murray JE, Haber M, Murray DN. The MYCN Oncogene. 2013.

21. Chen L, Tweddle DA. p53, SKP2, and DKK3 as MYCN target genes and their potential therapeutic significance. Front Oncol. 2012;2:173.

22. Fu J, Bian M, Jiang Q, Zhang C. Roles of Aurora kinases in mitosis and tumorigenesis. Mol Cancer Res. 2007;5:1-10.

23. Otto T, Horn S, Brockmann M, Eilers U, Schuttrumpf L, Popov N, Kenney AM, Schulte JH, Beijersbergen R, Christiansen $\mathrm{H}$, et al. Stabilization of N-Myc is a critical function of Aurora A in human neuroblastoma. Cancer Cell. 2009;15:67-78.

24. Shang X, Burlingame SM, Okcu MF, Ge N, Russell HV, Egler RA, David RD, Vasudevan SA, Yang J, Nuchtern JG. Aurora A is a negative prognostic factor and a new therapeutic target in human neuroblastoma. Mol Cancer Ther. 2009;8:2461-9.

25. Bogen D, Wei JS, Azorsa DO, Ormanoglu P, Buehler E, Guha R, Keller JM, Mathews Griner LA, Ferrer M, Song YK, et al. Aurora B kinase is a potent and selective target in MYCN-driven neuroblastoma. Oncotarget. 2015;6:35247-62.

26. Brockmann $M$, Poon E, Berry $T$, Carstensen A, Deubzer HE, Rycak L, Jamin $Y$, Thway K, Robinson SP, Roels F, et al. Small molecule inhibitors of aurora-a induce proteasomal degradation of $\mathrm{N}$-myc in childhood neuroblastoma. Cancer Cell. 2013;24:75-89.

27. Manfredi MG, Ecsedy JA, Chakravarty A, Silverman L, Zhang M, Hoar KM, Stroud SG, Chen W, Shinde V, Huck JJ, et al. Characterization of Alisertib (MLN8237), an investigational small-molecule inhibitor of aurora A kinase using novel in vivo pharmacodynamic assays. Clin Cancer Res. 2011;17:7614-24.

28. Manfredi MG, Ecsedy JA, Meetze KA, Balani SK, Burenkova O, Chen W, Galvin KM, Hoar KM, Huck JJ, Leroy PJ, et al. Antitumor activity of MLN8054, an orally active small-molecule inhibitor of Aurora A kinase. Proc Natl Acad Sci U S A. 2007:104:4106-11.

29. Mosse YP, Lipsitz E, Fox E, Teachey DT, Maris JM, Weigel B, Adamson PC, Ingle MA, Ahern $\mathrm{CH}$, Blaney SM. Pediatric phase I trial and pharmacokinetic study of MLN8237, an investigational oral selective small-molecule inhibitor of Aurora kinase A: a Children's Oncology Group Phase I Consortium study. Clin Cancer Res. 2012;18:6058-64.

30. Gustafson WC, Meyerowitz JG, Nekritz EA, Chen J, Benes C, Charron E, Simonds EF, Seeger R, Matthay KK, Hertz NT, et al. Drugging MYCN through an allosteric transition in Aurora kinase A. Cancer Cell. 2014;26:414-27.

31. Richards MW, Burgess SG, Poon E, Carstensen A, Eilers M, Chesler L, Bayliss R. Structural basis of N-Myc binding by Aurora-A and its destabilization by kinase inhibitors. Proc Natl Acad Sci U S A. 2016;113:13726-31.
32. Faisal A, Vaughan L, Bavetsias V, Sun C, Atrash B, Avery S, Jamin Y, Robinson SP, Workman P, Blagg J, et al. The aurora kinase inhibitor CCT137690 downregulates MYCN and sensitizes MYCN-amplified neuroblastoma in vivo. Mol Cancer Ther. 2011;10:2115-23.

33. Harrington EA, Bebbington D, Moore J, Rasmussen RK, Ajose-Adeogun AO, Nakayama T, Graham JA, Demur C, Hercend T, Diu-Hercend A, et al. VX-680, a potent and selective small-molecule inhibitor of the Aurora kinases, suppresses tumor growth in vivo. Nat Med. 2004;10:262-7.

34. Michaelis M, Selt F, Rothweiler F, Loschmann N, Nusse B, Dirks WG, Zehner R, Cinatl Jr J. Aurora kinases as targets in drug-resistant neuroblastoma cells. PLoS One. 2014;9:e108758.

35. Wenzel A, Schwab M. The mycN/max protein complex in neuroblastoma. Short review. Eur J Cancer. 1995:31A:516-9.

36. Muller I, Larsson K, Frenzel A, Oliynyk G, Zirath H, Prochownik EV, Westwood NJ, Henriksson MA. Targeting of the MYCN protein with small molecule c-MYC inhibitors. PLoS One. 2014;9:e97285.

37. Puissant A, Frumm SM, Alexe G, Bassil CF, Qi J, Chanthery YH, Nekritz EA Zeid R, Gustafson WC, Greninger P, et al. Targeting MYCN in neuroblastoma by BET bromodomain inhibition. Cancer Discov. 2013;3:308-23.

38. Althoff K, Beckers A, Bell E, Nortmeyer M, Thor T, Sprussel A, Lindner S, De Preter K, Florin A, Heukamp LC, et al. A Cre-conditional MYCN-driven neuroblastoma mouse model as an improved tool for preclinical studies. Oncogene. 2015;34:3357-68.

39. Henssen A, Althoff K, Odersky A, Beckers A, Koche R, Speleman F, Schafers S, Bell E, Nortmeyer M, Westermann F, et al. Targeting MYCN-Driven Transcription By BET-Bromodomain Inhibition. Clin Cancer Res. 2015:22:2470-81.

40. Barbieri E, Mehta P, Chen Z, Zhang L, Slack A, Berg S, Shohet JM. MDM2 inhibition sensitizes neuroblastoma to chemotherapy-induced apoptotic cell death. Mol Cancer Ther. 2006;5:2358-65.

41. Evageliou NF, Hogarty MD. Disrupting polyamine homeostasis as a therapeutic strategy for neuroblastoma. Clin Cancer Res. 2009;15:5956-61.

42. Di Giannatale A, Dias-Gastellier N, Devos A, Mc Hugh K, Boubaker A Courbon F, Verschuur A, Ducassoul S, Malekzadeh K, Casanova M, et al. Phase II study of temozolomide in combination with topotecan (TOTEM) in relapsed or refractory neuroblastoma: a European Innovative Therapies for Children with Cancer-SIOP-European Neuroblastoma study. Eur J Cancer. 2014;50:170-7.

43. Vogan K, Bernstein M, Leclerc JM, Brisson L, Brossard J, Brodeur GM, Pelletier J, Gros P. Absence of p53 gene mutations in primary neuroblastomas. Cancer Res. 1993:53:5269-73.

44. Barone G, Tweddle DA, Shohet JM, Chesler L, Moreno L, Pearson AD, Van Maerken T. MDM2-p53 interaction in paediatric solid tumours: preclinical rationale, biomarkers and resistance. Curr Drug Targets. 2014;15:114-23.

45. Tweddle DA, Pearson AD, Haber M, Norris MD, Xue C, Flemming C, Lunec J. The 053 pathway and its inactivation in neuroblastoma. Cancer Lett. 2003;197:93-8.

46. Carr J, Bell E, Pearson AD, Kees UR, Beris H, Lunec J, Tweddle DA. Increased frequency of aberrations in the p53/MDM2/p14(ARF) pathway in neuroblastoma cell lines established at relapse. Cancer Res. 2006;66:2138-45.

47. Carr-Wilkinson J, OToole K, Wood KM, Challen CC, Baker AG, Board JR, Evans L, Cole M, Cheung NK, Boos J, et al. High frequency of p53/MDM2/ p14ARF pathway abnormalities in relapsed neuroblastoma. Clin Cancer Res. 2010;16:1108-18.

48. Chen Z, Lin Y, Barbieri E, Burlingame S, Hicks J, Ludwig A, Shohet JM. Mdm2 deficiency suppresses MYCN-Driven neuroblastoma tumorigenesis in vivo. Neoplasia. 2009;11:753-62.

49. Barbieri E, De Preter K, Capasso M, Johansson P, Man TK, Chen Z, Stowers P Tonini GP, Speleman F, Shohet JM. A p53 drug response signature identifies prognostic genes in high-risk neuroblastoma. PLoS One. 2013:8:e79843.

50. Kim E, Shohet J. Targeted molecular therapy for neuroblastoma: the ARF/ MDM2/p53 axis. J Natl Cancer Inst. 2009;101:1527-9.

51. Swarbrick A, Woods SL, Shaw A, Balakrishnan A, Phua Y, Nguyen A, Chanthery Y, Lim L, Ashton $L$, Judson RL, et al. miR-380-5p represses p53 to control cellular survival and is associated with poor outcome in MYCN-amplified neuroblastoma. Nat Med. 2010;16:1134-40.

52. Maiuri MC, Galluzzi L, Morselli E, Kepp O, Malik SA, Kroemer G. Autophagy regulation by p53. Curr Opin Cell Biol. 2010;22:181-5.

53. Wolter J, Angelini P, Irwin M. p53 family: Therapeutic targets in neuroblastoma. Future Oncol. 2010;6:429-44.

54. Khoo KH, Verma CS, Lane DP. Drugging the p53 pathway: understanding the route to clinical efficacy. Nat Rev Drug Discov. 2014;13:217-36. 
55. Gamble LD, Kees UR, Tweddle DA, Lunec J. MYCN sensitizes neuroblastoma to the MDM2-p53 antagonists Nutlin-3 and MI-63. Oncogene. 2012;31:752-63.

56. Wang P, Greiner TC, Lushnikova T, Eischen CM. Decreased Mdm2 expression inhibits tumor development induced by loss of ARF. Oncogene. 2006;25: 3708-18.

57. Michaelis M, Rothweiler F, Klassert D, von Deimling A, Weber K, Fehse B, Kammerer B, Doerr HW, Cinatl Jr J. Reversal of P-glycoprotein-mediated multidrug resistance by the murine double minute 2 antagonist nutlin-3. Cancer Res. 2009;69:416-21.

58. Chen L, Zhao Y, Halliday GC, Berry P, Rousseau RF, Middleton SA, Nichols GL, Del Bello F, Piergentili A, Newell DR, et al. Structurally diverse MDM2-p53 antagonists act as modulators of MDR-1 function in neuroblastoma. $\mathrm{Br} \mathrm{J}$ Cancer. 2014;111:716-25.

59. Jeay S, Gaulis S, Ferretti S, Bitter H, Ito M, Valat T, Murakami M, Ruetz S, Guthy DA, Rynn C, et al. A distinct p53 target gene set predicts for response to the selective p53-HDM2 inhibitor NVP-CGM097. Elife. 2015;4:e06498.

60. Gessier F, Kallen J, Jacoby E, Chene P, Stachyra-Valat T, Ruetz S, Jeay S, Holzer $P$, Masuya K, Furet P. Discovery of dihydroisoquinolinone derivatives as novel inhibitors of the p53-MDM2 interaction with a distinct binding mode. Bioorg Med Chem Lett. 2015;25:3621-5.

61. Hogarty MD, Norris MD, Davis K, Liu X, Evageliou N, Hayes CS, Pawel B, Guo $R$, Zhao $H$, Sekyere $E$, et al. ODC1 is a critical determinant of MYCN oncogenesis and a therapeutic target in neuroblastoma. Cancer Res. 2008; 68:9735-45.

62. Saulnier Sholler GL, Gerner EW, Bergendahl G, Macarthur RB, Vanderwerff A, Ashikaga T, Bond JP, Ferguson W, Roberts W, Wada RK, et al. A phase I trial of DFMO targeting polyamine addiction in patients with relapsed/refractory neuroblastoma. PLoS One. 2015:10:e0127246.

63. Bassiri H, Benavides A, Haber M, Gilmour SK, Norris MD, Hogarty MD. Translational development of difluoromethylornithine (DFMO) for the treatment of neuroblastoma. Transl Pediatr. 2015;4:226-38.

64. Wallick CJ, Gamper I, Thorne M, Feith DJ, Takasaki KY, Wilson SM, Seki JA Pegg AE, Byus CV, Bachmann AS. Key role for p27Kip1, retinoblastoma protein $\mathrm{Rb}$, and MYCN in polyamine inhibitor-induced G1 cell cycle arrest in MYCN-amplified human neuroblastoma cells. Oncogene. 2005;24:5606-18.

65. Sarbassov DD, Ali SM, Sabatini DM. Growing roles for the mTOR pathway. Curr Opin Cell Biol. 2005;17:596-603.

66. Vaughan L, Clarke PA, Barker K, Chanthery Y, Gustafson CW, Tucker E, Renshaw J, Raynaud F, Li X, Burke R, et al. Inhibition of mTOR-kinase destabilizes MYCN and is a potential therapy for MYCN-dependent tumors. Oncotarget. 2016;7:57525-44.

67. Osajima-Hakomori Y, Miyake I, Ohira M, Nakagawara A, Nakagawa A, Sakai R. Biological role of anaplastic lymphoma kinase in neuroblastoma. Am J Pathol. 2005:167:213-22.

68. Palmer RH, Vernersson E, Grabbe C, Hallberg B. Anaplastic lymphoma kinase: signalling in development and disease. Biochem J. 2009;420:345-61.

69. Schulte JH, Schulte S, Heukamp LC, Astrahantseff K, Stephan H, Fischer M, Schramm A, Eggert A. Targeted therapy for neuroblastoma: ALK inhibitors. Klin Padiatr. 2013;225:303-8.

70. Esposito M, Aveic S, Seydel A, Tonini G. The role of omics in neuroblastoma: Patient's risk classification and personalised therapy. Adv Modern Oncol. 2016:2:271-78.

71. Chen Y, Takita J, Choi YL, Kato M, Ohira M, Sanada M, Wang L, Soda M, Kikuchi A, Igarashi T, et al. Oncogenic mutations of ALK kinase in neuroblastoma. Nature. 2008:455:971-4.

72. Mosse YP, Laudenslager M, Longo L, Cole KA, Wood A, Attiyeh EF, Laquaglia MJ, Sennett R, Lynch JE, Perri P, et al. Identification of ALK as a major familial neuroblastoma predisposition gene. Nature. 2008;455:930-5.

73. Futami H, Sakai R. All-trans retinoic acid downregulates ALK in neuroblastoma cell lines and induces apoptosis in neuroblastoma cell lines with activated ALK. Cancer Lett. 2010;297:220-5.

74. Wellstein A, Toretsky JA. Hunting ALK to feed targeted cancer therapy. Nat Med. 2011;17:290-1.

75. Moog-Lutz C, Degoutin J, Gouzi JY, Frobert Y, Brunet-De Carvalho N Bureau J, Creminon C, Vigny M. Activation and inhibition of anaplastic lymphoma kinase receptor tyrosine kinase by monoclonal antibodies and absence of agonist activity of pleiotrophin. J Biol Chem. 2005;280:26039-48.

76. Carpenter EL, Mosse YP. Targeting ALK in neuroblastoma-preclinical and clinical advancements. Nat Rev Clin Oncol. 2012;9:391-9.

77. Wood AC, Laudenslager M, Haglund EA, Attiyeh EF, Pawel B, Courtright J, Plegaria J, Christensen JG, Maris JM, Mosse YP. Inhibition of ALK mutated neuroblastomas by the selective inhibitor PF-02341066. J Clin Oncol. 2009; 27:10008b.

78. Mosse YP, Deyell RJ, Berthold F, Nagakawara A, Ambros PF, Monclair T, Cohn SL, Pearson AD, London WB, Matthay KK. Neuroblastoma in older children, adolescents and young adults: a report from the International Neuroblastoma Risk Group project. Pediatr Blood Cancer. 2014;61:627-35.

79. Bresler SC, Weiser DA, Huwe PJ, Park JH, Krytska K, Ryles H, Laudenslager M, Rappaport EF, Wood AC, Mcgrady PW, et al. ALK mutations confer differential oncogenic activation and sensitivity to ALK inhibition therapy in neuroblastoma. Cancer Cell. 2014;26:682-94.

80. Berry T, Luther W, Bhatnagar N, Jamin Y, Poon E, Sanda T, Pei D, Sharma B, Vetharoy WR, Hallsworth A, et al. The ALK (F1174L) mutation potentiates the oncogenic activity of MYCN in neuroblastoma. Cancer Cell. 2012;22:117-30.

81. Krytska K, Ryles HT, Sano R, Raman P, Infarinato NR, Hansel TD, Makena MR, Song MM, Reynolds CP, Mosse YP. Crizotinib synergizes with chemotherapy in preclinical models of neuroblastoma. Clin Cancer Res. 2016;22:948-60.

82. Huang D, Kim DW, Kotsakis A, Deng S, Lira P, Ho SN, Lee NV, Vizcarra P, Cao JQ, Christensen JG, et al. Multiplexed deep sequencing analysis of ALK kinase domain identifies resistance mutations in relapsed patients following crizotinib treatment. Genomics. 2013;102:157-62.

83. Lee J, Kim HC, Hong JY, Wang K, Kim SY, Jang J, Kim ST, Park JO, Lim HY, Kang WK, et al. Detection of novel and potentially actionable anaplastic lymphoma kinase (ALK) rearrangement in colorectal adenocarcinoma by immunohistochemistry screening. Oncotarget. 2015;6:24320-32.

84. Aveic S, Pantile M, Seydel A, Esposito MR, Zanon C, Li G, Tonini GP. Combating autophagy is a strategy to increase cytotoxic effects of novel ALK inhibitor entrectinib in neuroblastoma cells. Oncotarget. 2016;7:5646-63.

85. Iyer R, Wehrmann L, Golden RL, Naraparaju K, Croucher JL, Macfarland SP, Guan P, Kolla V, Wei G, Cam N, et al. Entrectinib is a potent inhibitor of Trk-driven neuroblastomas in a xenograft mouse model. Cancer Lett. 2016;372:179-86.

86. Mckeage K. Alectinib: a review of its use in advanced ALK-rearranged non-small cell lung cancer. Drugs. 2015;75:75-82.

87. Moore NF, Azarova AM, Bhatnagar N, Ross KN, Drake LE, Frumm S, Liu QS, Christie AL, Sanda T, Chesler $L$, et al. Molecular rationale for the use of PI3K/AKT/mTOR pathway inhibitors in combination with crizotinib in ALK-mutated neuroblastoma. Oncotarget. 2014;5:8737-49.

88. Infarinato NR, Park JH, Krytska K, Ryles HT, Sano R, Szigety KM, Li Y, Zou HY, Lee NV, Smeal T, et al. The ALK/ROS1 inhibitor PF-06463922 overcomes primary resistance to crizotinib in ALK-driven neuroblastoma. Cancer Discov. 2016;6:96-107.

89. Scaruffi P, Cusano R, Dagnino M, Tonini GP. Detection of DNA polymorphisms and point mutations of high-affinity nerve growth factor receptor (TrkA) in human neuroblastoma. Int J Oncol. 1999;14:935-8.

90. Nakagawara A, Liu XG, Ikegaki N, White PS, Yamashiro DJ, Nycum LM, Biegel JA, Brodeur GM. Cloning and chromosomal localization of the human TRK-B tyrosine kinase receptor gene (NTRK2). Genomics. 1995;25:538-46.

91. Nakagawara A, Azar CG, Scavarda NJ, Brodeur GM. Expression and function of TRK-B and BDNF in human neuroblastomas. Mol Cell Biol. 1994;14:759-67.

92. Ho R, Eggert A, Hishiki T, Minturn JE, Ikegaki N, Foster P, Camoratto AM, Evans AE, Brodeur GM. Resistance to chemotherapy mediated by TrkB in neuroblastomas. Cancer Res. 2002;62:6462-6.

93. Acheson A, Conover JC, Fandl JP, Dechiara TM, Russell M, Thadani A, Squinto SP, Yancopoulos GD, Lindsay RM. A BDNF autocrine loop in adult sensory neurons prevents cell death. Nature. 1995;374:450-3.

94. Matsumoto K, Wada RK, Yamashiro JM, Kaplan DR, Thiele CJ. Expression of brain-derived neurotrophic factor and p145TrkB affects survival, differentiation, and invasiveness of human neuroblastoma cells. Cancer Res. 1995;55:1798-806

95. Brodeur GM. Neuroblastoma: biological insights into a clinical enigma. Nat Rev Cancer. 2003:3:203-16.

96. Croucher JL, Iyer R, Li N, Molteni V, Loren J, Gordon WP, Tuntland T, Liu B, Brodeur GM. TrkB inhibition by GNF-4256 slows growth and enhances chemotherapeutic efficacy in neuroblastoma xenografts. Cancer Chemother Pharmacol. 2015:75:131-41.

97. Li Z, Zhang Y, Tong Y, Tong J, Thiele CJ. Trk inhibitor attenuates the BDNF/ TrkB-induced protection of neuroblastoma cells from etoposide in vitro and in vivo. Cancer Biol Ther. 2015;16:477-83.

98. Nakamura Y, Suganami A, Fukuda M, Hasan MK, Yokochi T, Takatori A, Satoh S, Hoshino T, Tamura Y, Nakagawara A. Identification of novel candidate compounds targeting TrkB to induce apoptosis in neuroblastoma. Cancer Med. 2014;3:25-35 
99. King D, Yeomanson D, Bryant HE. PI3King the lock: targeting the PI3K/Akt/ mTOR pathway as a novel therapeutic strategy in neuroblastoma. J Pediatr Hematol Oncol. 2015;37:245-51.

100. Segerstrom L, Baryawno N, Sveinbjornsson B, Wickstrom M, Elfman L, Kogner $P$, Johnsen Jl. Effects of small molecule inhibitors of PI3K/Akt/mTOR signaling on neuroblastoma growth in vitro and in vivo. Int J Cancer. 2011;129:2958-65

101. Pal I, Mandal M. PI3K and Akt as molecular targets for cancer therapy: current clinical outcomes. Acta Pharmacol Sin. 2012;33:1441-58.

102. Mei H, Wang $Y$, Lin Z, Tong $Q$. The mTOR signaling pathway in pediatric neuroblastoma. Pediatr Hematol Oncol. 2013;30:605-15.

103. Westhoff MA, Faham N, Marx D, Nonnenmacher $L$, Jennewein $C$, Enzenmuller S, Gonzalez P, Fulda S, Debatin KM. Sequential dosing in chemosensitization: targeting the PI3K/Akt/mTOR pathway in neuroblastoma. PLoS One. 2013:8:e83128.

104. Rodrik-Outmezguine VS, Chandarlapaty S, Pagano NC, Poulikakos PI, Scaltriti M, Moskatel E, Baselga J, Guichard S, Rosen N. mTOR kinase inhibition causes feedback-dependent biphasic regulation of AKT signaling. Cancer Discov. 2011;1:248-59.

105. Geoerger B, Kieran MW, Grupp S, Perek D, Clancy J, Krygowski M, Ananthakrishnan R, Boni JP, Berkenblit A, Spunt SL. Phase II trial of temsirolimus in children with high-grade glioma, neuroblastoma and rhabdomyosarcoma. Eur J Cancer. 2012;48:253-62.

106. Islam A, Kageyama H, Takada N, Kawamoto T, Takayasu H, Isogai E, Ohira M, Hashizume K, Kobayashi H, Kaneko Y, Nakagawara A. High expression of Survivin, mapped to $17 q 25$, is significantly associated with poor prognostic factors and promotes cell survival in human neuroblastoma. Oncogene. 2000;19:617-23.

107. Houghton PJ, Morton CL, Tucker C, Payne D, Favours E, Cole C, Gorlick R, Kolb EA, Zhang W, Lock $R$, et al. The pediatric preclinical testing program: description of models and early testing results. Pediatr Blood Cancer. 2007:49:928-40.

108. Lamers F, Schild L, Koster J, Versteeg R, Caron HN, Molenaar JJ. Targeted BIRC5 silencing using YM155 causes cell death in neuroblastoma cells with low ABCB1 expression. Eur J Cancer. 2012;48:763-71.

109. Voges $Y$, Michaelis M, Rothweiler F, Schaller T, Schneider C, Politt K, Mernberger M, Nist A, Stiewe T, Wass MN, et al. Effects of YM155 on survivin levels and viability in neuroblastoma cells with acquired drug resistance. Cell Death Dis. 2016;7:e2410.

110. Barille-Nion S, Bah N, Vequaud E, Juin P. Regulation of cancer cell survival by BCL2 family members upon prolonged mitotic arrest: opportunities for anticancer therapy. Anticancer Res. 2012;32:4225-33.

111. Cory S, Adams JM. The Bcl2 family: regulators of the cellular life-or-death switch. Nat Rev Cancer. 2002;2:647-56.

112. Goldsmith KC, Hogarty MD. Targeting programmed cell death pathways with experimental therapeutics: opportunities in high-risk neuroblastoma. Cancer Lett. 2005;228:133-41.

113. Lestini BJ, Goldsmith KC, Fluchel MN, Liu X, Chen NL, Goyal B, Pawel BR, Hogarty MD. Mcl1 downregulation sensitizes neuroblastoma to cytotoxic chemotherapy and small molecule Bcl2-family antagonists. Cancer Biol Ther. 2009;8:1587-95.

114. Lamers F, Schild L, den Hartog IJ, Ebus ME, Westerhout EM, Ora I, Koster J, Versteeg R, Caron HN, Molenaar JJ. Targeted BCL2 inhibition effectively inhibits neuroblastoma tumour growth. Eur J Cancer. 2012;48:3093-103.

115. Banerji U. Heat shock protein 90 as a drug target: some like it hot Clin Cancer Res. 2009;15:9-14.

116. Kamal A, Burrows FJ. Hsp90 inhibitors as selective anticancer drugs. Discov Med. 2004:4:277-80

117. Regan PL, Jacobs J, Wang G, Torres J, Edo R, Friedmann J, Tang XX. Hsp90 inhibition increases p53 expression and destabilizes MYCN and MYC in neuroblastoma. Int J Oncol. 2011;38:105-12.

118. Sidarovich V, Adami V, Gatto P, Greco V, Tebaldi T, Tonini GP, Quattrone A. Translational downregulation of HSP90 expression by iron chelators in neuroblastoma cells. Mol Pharmacol. 2015;87:513-24.

119. Lasorsa VA, Formicola D, Pignataro P, Cimmino F, Calabrese FM, Mora J, Esposito MR, Pantile M, Zanon C, De Mariano M, et al. Exome and deep sequencing of clinically aggressive neuroblastoma reveal somatic mutations that affect key pathways involved in cancer progression. Oncotarget. 2016;7:21840-52.

120. Molenaar JJ, Koster J, Zwijnenburg DA, van Sluis $P$, Valentijn $L J$, van der Ploeg I, Hamdi M, van Nes J, Westerman BA, van Arkel J, et al. Sequencing of neuroblastoma identifies chromothripsis and defects in neuritogenesis genes. Nature. 2012;483:589-93.

121. Peifer M, Hertwig F, Roels F, Dreidax D, Gartlgruber M, Menon R, Kramer A, Roncaioli JL, Sand F, Heuckmann JM, et al. Telomerase activation by genomic rearrangements in high-risk neuroblastoma. Nature. 2015;526:700-4.

122. Pugh TJ, Morozova O, Attiyeh EF, Asgharzadeh S, Wei JS, Auclair D, Carter SL, Cibulskis K, Hanna M, Kiezun A, et al. The genetic landscape of high-risk neuroblastoma. Nat Genet. 2013;45:279-84.

123. Sausen M, Leary RJ, Jones S, Wu J, Reynolds CP, Liu X, Blackford A, Parmigiani G, Diaz Jr LA, Papadopoulos N, et al. Integrated genomic analyses identify ARID1A and ARID1B alterations in the childhood cancer neuroblastoma. Nat Genet. 2013;45:12-7.

124. Valentijn $\sqcup$, Koster J, Zwijnenburg DA, Hasselt NE, van Sluis P, Volckmann R, van Noesel MM, George RE, Tytgat GA, Molenaar JJ, Versteeg R. TERT rearrangements are frequent in neuroblastoma and identify aggressive tumors. Nat Genet. 2015;47:1411-4

125. Riehl LM, Schulte JH, Mulaw MA, Dahlhaus M, Fischer M, Schramm A Eggert A, Debatin KM, Beltinger C. The mitochondrial genetic landscape in neuroblastoma from tumor initiation to relapse. Oncotarget. 2016;7:6620-5.

126. Schramm A, Koster J, Assenov Y, Althoff K, Peifer M, Mahlow E, Odersky A, Beisser D, Ernst C, Henssen AG, et al. Mutational dynamics between primary and relapse neuroblastomas. Nat Genet. 2015;47:872-7.

127. Eleveld TF, Oldridge DA, Bernard V, Koster J, Daage LC, Diskin SJ, Schild L, Bentahar NB, Bellini A, Chicard M, et al. Relapsed neuroblastomas show frequent RAS-MAPK pathway mutations. Nat Genet. 2015;47:864-71.

128. Ramaswamy $V$, Taylor MD. Pediatric cancer genomics, a play rather than a portrait. Nat Genet. 2015;47:851-2.

129. Farshidfar F, Weljie AM, Kopciuk K, Buie WD, Maclean A, Dixon E, Sutherland FR, Molckovsky A, Vogel HJ, Bathe OF. Serum metabolomic profile as a means to distinguish stage of colorectal cancer. Genome Med. 2012;4:42.

130. Gika HG, Theodoridis GA, Wilson ID. Liquid chromatography and ultraperformance liquid chromatography-mass spectrometry fingerprinting of human urine: sample stability under different handling and storage conditions for metabonomics studies. J Chromatogr A. 2008:1189:314-22

131. Odunsi K, Wollman RM, Ambrosone CB, Hutson A, McCann SE, Tammela J, Geisler JP, Miller G, Sellers T, Cliby W, et al. Detection of epithelial ovarian cancer using 1H-NMR-based metabonomics. Int J Cancer. 2005;113:782-8.

132. Imperiale A, Elbayed K, Moussallieh FM, Neuville A, Piotto M, Bellocq JP, Lutz P, Namer IJ. Metabolomic pattern of childhood neuroblastoma obtained by (1) H-high-resolution magic angle spinning (HRMAS) NMR spectroscopy. Pediatr Blood Cancer. 2011;56:24-34.

133. Beaudry P, Campbell M, Dang NH, Wen J, Blote K, Weljie AM. A pilot study on the utility of serum metabolomics in neuroblastoma patients and xenograft models. Pediatr Blood Cancer. 2016;63:214-20.

134. Egler RA, Li Y, Dang TA, Peters TL, Leung E, Huang S, Russell HV, Liu H, Man TK. An integrated proteomic approach to identifying circulating biomarkers in high-risk neuroblastoma and their potential in relapse monitoring. Proteomics Clin Appl. 2011;5:532-41.

135. Otake K, Uchida K, Ide S, Kobayashi Y, Kobayashi I, Kusunoki M. Identification of DDX39A as a potential biomarker for unfavorable neuroblastoma using a proteomic approach. Pediatr Blood Cancer. 2016;63:221-7.

136. Emdal KB, Pedersen AK, Bekker-Jensen DB, Tsafou KP, Horn H, Lindner S, Schulte JH, Eggert A, Jensen LJ, Francavilla C, Olsen JV. Temporal proteomics of NGF-TrkA signaling identifies an inhibitory role for the E3 ligase Cbl-b in neuroblastoma cell differentiation. Sci Signal. 2015;8:ra40.

137. Ren X, Bai X, Zhang X, Li Z, Tang L, Zhao X, Ren Y, Wei S, Wang Q, Liu C, Ji J. Quantitative nuclear proteomics identifies that miR-137-mediated EZH2 reduction regulates resveratrol-induced apoptosis of neuroblastoma cells. Mol Cell Proteomics. 2015;14:316-28.

138. Houghton PJ, Adamson PC, Blaney S, Fine HA, Gorlick R, Haber M, Helman L, Hirschfeld S, Hollingshead MG, Israel MA, et al. Testing of new agents in childhood cancer preclinical models: meeting summary. Clin Cancer Res. 2002;8:3646-57.

139. Di Zanni E, Fornasari D, Ravazzolo R, Ceccherini I, Bachetti T. Identification of novel pathways and molecules able to down-regulate PHOX2B gene expression by in vitro drug screening approaches in neuroblastoma cells. Exp Cell Res. 2015;336:43-57.

140. Harder N, Batra R, DiessI N, Gogolin S, Eils R, Westermann F, Konig R, Rohr K. Large-scale tracking and classification for automatic analysis of cell migration 
and proliferation, and experimental optimization of high-throughput screens of neuroblastoma cells. Cytometry A. 2015;87:524-40.

141. Gargiulo G, Minucci S. Epigenomic profiling of cancer cells. Int J Biochem Cell Biol. 2009:41:127-35.

142. Decock A, Ongenaert M, Hoebeeck J, De Preter K, Van Peer G, Van Criekinge W, Ladenstein R, Schulte JH, Noguera R, Stallings RL, et al. Genome-wide promoter methylation analysis in neuroblastoma identifies prognostic methylation biomarkers. Genome Biol. 2012;13:R95.

143. Lazcoz P, Munoz J, Nistal M, Pestana A, Encio I, Castresana JS. Frequent promoter hypermethylation of RASSF1A and CASP8 in neuroblastoma. BMC Cancer. 2006;6:254.

144. Gomez S, Castellano G, Mayol G, Sunol M, Queiros A, Bibikova M, Nazor KL, Loring JF, Lemos I, Rodriguez $\mathrm{E}$, et al. DNA methylation fingerprint of neuroblastoma reveals new biological and clinical insights. Epigenomics. 2015:7:1137-53.

145. Buckley PG, Das S, Bryan K, Watters KM, Alcock L, Koster J, Versteeg R, Stallings RL. Genome-wide DNA methylation analysis of neuroblastic tumors reveals clinically relevant epigenetic events and large-scale epigenomic alterations localized to telomeric regions. Int J Cancer. 2011;128:2296-305.

146. Althoff K, Lindner S, Odersky A, Mestdagh P, Beckers A, Karczewski S, Molenaar JJ, Bohrer A, Knauer S, Speleman F, et al. miR-542-3p exerts tumor suppressive functions in neuroblastoma by downregulating Survivin. Int J Cancer. 2015;136:1308-20.

147. Hsu CL, Chang HY, Chang JY, Hsu WM, Huang HC, Juan HF. Unveiling MYCN regulatory networks in neuroblastoma via integrative analysis of heterogeneous genomics data. Oncotarget. 2016;7:36293-310.

148. Scaruffi P, Stigliani S, Moretti S, Coco S, De Vecchi C, Valdora F, Garaventa A, Bonassi S, Tonini GP. Transcribed-ultra conserved region expression is associated with outcome in high-risk neuroblastoma. BMC Cancer. 2009:9:441.

149. Buhagiar A, Ayers D. Chemoresistance, cancer stem cells, and miRNA influences: the case for neuroblastoma. Anal Cell Pathol (Amst). 2015; 2015:150634.

150. Mestdagh P, Bostrom AK, Impens F, Fredlund E, Van Peer G, De Antonellis $P$, von Stedingk K, Ghesquiere B, Schulte S, Dews M, et al. The miR-17-92 microRNA cluster regulates multiple components of the TGF-beta pathway in neuroblastoma. Mol Cell. 2010;40:762-73.

151. Pandey GK, Mitra S, Subhash S, Hertwig F, Kanduri M, Mishra K, Fransson S, Ganeshram A, Mondal T, Bandaru S, et al. The risk-associated long noncoding RNA NBAT-1 controls neuroblastoma progression by regulating cell proliferation and neuronal differentiation. Cancer Cell. 2014;26:722-37.

152. Sahu D, Hsu CL, Lin CC, Yang TW, Hsu WM, Ho SY, Juan HF, Huang HC. Co-expression analysis identifies long noncoding RNA SNHG1 as a novel predictor for event-free survival in neuroblastoma. Oncotarget. 2016;7: 58022-37.

153. Bettegowda C, Sausen M, Leary RJ, Kinde I, Wang Y, Agrawal N, Bartlett BR, Wang H, Luber B, Alani RM, et al. Detection of circulating tumor DNA in early- and late-stage human malignancies. Sci Transl Med. 2014;6:224ra224.

154. Kurihara S, Ueda Y, Onitake Y, Sueda T, Ohta E, Morihara N, Hirano S, Irisuna F, Hiyama E. Circulating free DNA as non-invasive diagnostic biomarker for childhood solid tumors. J Pediatr Surg. 2015;50:2094-7.

155. Rifatbegovic F, Abbasi MR, Taschner-Mandl S, Kauer M, Weinhausel A, Handgretinger R, Ambros PF. Enriched bone marrow derived disseminated neuroblastoma cells can be a reliable source for gene expression studies-a validation study. PLoS One. 2015;10:e0137995.

156. Murtaza M, Dawson SJ, Pogrebniak K, Rueda OM, Provenzano E, Grant J, Chin SF, Tsui DW, Marass F, Gale D, et al. Multifocal clonal evolution characterized using circulating tumour DNA in a case of metastatic breast cancer. Nat Commun. 2015;6:8760.

\section{Submit your next manuscript to BioMed Central and we will help you at every step:}

- We accept pre-submission inquiries

- Our selector tool helps you to find the most relevant journal

- We provide round the clock customer support

- Convenient online submission

- Thorough peer review

- Inclusion in PubMed and all major indexing services

- Maximum visibility for your research

Submit your manuscript at www.biomedcentral.com/submit 